\title{
Neonatal Seizures in Monkeys and Rabbits: Brain Glucose Depletion in the Face of Normoglycemia, Prevention by Glucose Loads
}

\author{
BARNEY E. DWYER AND CLAUDE G. WASTERLAIN \\ Epilepsy Research Laboratory, V.A. Medical Center, Sepulveda 91343 and the Department of Neurology and the \\ Brain Research Institute, U.C.L.A. School of Medicine, Los Angeles, California 90024
}

\begin{abstract}
Sustained convulsive seizures were induced with bicuculline in newborn rabbits and marmoset monkeys. In both species, seizures were predominantly tonic, with generalized polyspikes on the EEG. Brain glucose concentration fell dramatically during seizures in both species, and in many normoglycemic animals reached levels usually associated with severe hypoglycemia, suggesting that glucose transport from blood to brain could not keep pace with glucose utilization. Glucose loads given to rabbits induced hyperglycemia and during seizures maintained brain glucose well above concentrations needed to saturate hexokinase so that glycolytic rates were probably never limited by substrate availability. Blood and brain lactate concentrations rose during seizures but never reached levels considered cytotoxic. These data suggest that epileptic seizures can deplete brain glucose in normoglycemic neonates of several species, including subhuman primates. (Pediatr Res 19: 992-995, 1985)
\end{abstract}

Neonatal status epilepticus in rats can result in death or in stunted brain growth (1). During seizures brain glucose fell in these animals despite normal blood glucose levels (2). If rats were made hyperglycemic by injecting them with an isotonic glucose solution before seizure onset the mortality rate from status epilepticus was reduced by $90 \%$ during the 1 st wk of life, brain glucose was not depleted and deficits in brain growth were reduced (2). The purpose of this investigation was to determine whether these phenomena are peculiar to the rat or occur in other species including subhuman primates. We have induced generalized seizures with bicuculline, a plant alkaloid, which blocks the postsynaptic inhibitory action of GABA on neuronal firing rates (3). We have shown that continuous seizures can deplete brain glucose in newborn rabbits and marmoset monkeys, in the presence of normal blood glucose concentrations, and that brain glucose depletion in seizing rabbits can be prevented if animals are made hyperglycemic prior to seizure onset.

\section{MATERIALS AND METHODS}

Animals. Rabbits of either sex (12-24 h old) were purchased from Curd's Caviary and Animal Supply (LaPuente, CA). Marmoset monkeys (Callithrix jacchus) aged 4-7 days were obtained from our breeding colony at the Sepulveda V.A. Medical Center.

Received January 3, 1985; accepted May 16, 1985

Correspondence should be addressed to Dr. Barney E. Dwyer, Epilepsy Research Laboratory (111N-1), V.A.M.C., 16111 Plummer Street, Sepulveda, CA 91343.

Supported by Grant 13515 from NINCDS, the Research Service of the Veterans Administration, and the United Cerebral Palsy Research and Educational Foundation, Inc.
Epileptic Seizures. Animals were maintained in a $37^{\circ} \mathrm{C}$ water bath during the experiment. Seizures were induced by the intramuscular injection of bicuculline $\mathrm{HCl}(5 \mathrm{mg} / \mathrm{kg})$. Bicuculline obtained from Calbiochem (LaJolla, CA) was dissolved in $0.1 \mathrm{~N}$ $\mathrm{HCl}$ and the $\mathrm{pH}$ was adjusted to about 5 with $0.1 \mathrm{~N} \mathrm{NaHCO}_{3}$ shortly before use. The time of onset of seizures was taken as the time of the first tonic seizure, usually $2-3 \mathrm{~min}$ after bicuculline injection.

Tissue Sampling. Rabbits were subjected to microwave fixation (1-1.3 s) in the Metabostat model 4094 focused beam microwave oven (Gerling Moore; Palo Alto, CA) at various times after seizure onset. Blood was obtained from the decapitated trunk and fixed brain tissue was dissected from the skull. Marmosets $(30-50 \mathrm{~g})$ were immersed in liquid nitrogen with rapid agitation at times indicated in the text. Shortly before freezing, blood was obtained from the tail. Instruments were chilled in liquid nitrogen and the brain was chipped from the skull on dry ice. Tissues were repeatedly immersed in liquid nitrogen during the dissection and stored at $-70^{\circ} \mathrm{C}$ until processed.

Chemical Assays. Whole blood and brain tissue were homogenized in $1.2 \mathrm{~N}$ perchloric acid chilled in a dry ice-acetone bath. The sample was centrifuged at $100,000 \times g$ for $30 \mathrm{~min}$. The clear supernatant was neutralized with $\mathrm{KOH}$ and the insoluble $\mathrm{KClO}_{4}$ was pelleted and discarded. Glucose was measured using an oxidase/peroxidase colorimetric assay purchased in kit form from the Sigma Chemical Co. (St. Louis, MO). Lactate was measured by a spectrophotometric assay also purchased in kit form from Sigma. Brain glucose and lactate concentrations were corrected for the contribution from blood which was estimated to represent $3 \%$ of brain wet weight.

Experimental Design. Rabbits. Three groups of rabbits were studied: group 1 consisted of untreated animals and are referred to in the text as the control group. Animals in groups 2 and 3 received seizures induced with bicuculline. Group 2 rabbits were injected with $5 \%$ of body weight of an isotonic glucose solution [5.4\% D-glucose (w/v) $\mathrm{pH} 7.2] 30 \mathrm{~min}$ prior to bicuculline administration and are referred to in the text as "glucose-treated." Group 3 rabbits received an equivalent volume of $0.9 \% \mathrm{NaCl} 30$ min prior to bicuculline and served as a volume control. They are referred to in the text as "saline-treated."

Marmosets. Two groups of marmosets were studied: the control group $(n=3)$ was untreated. The seizure group $(n=9)$ received bicuculline alone to induce convulsions and were otherwise untreated.

The statistical significance of experimental data was determined by standard $t$ test analysis.

\section{RESULTS}

Epileptic seizures. Immediately after intramuscular injection of bicuculline, rabbits were quiet with a normal EEG; then the 

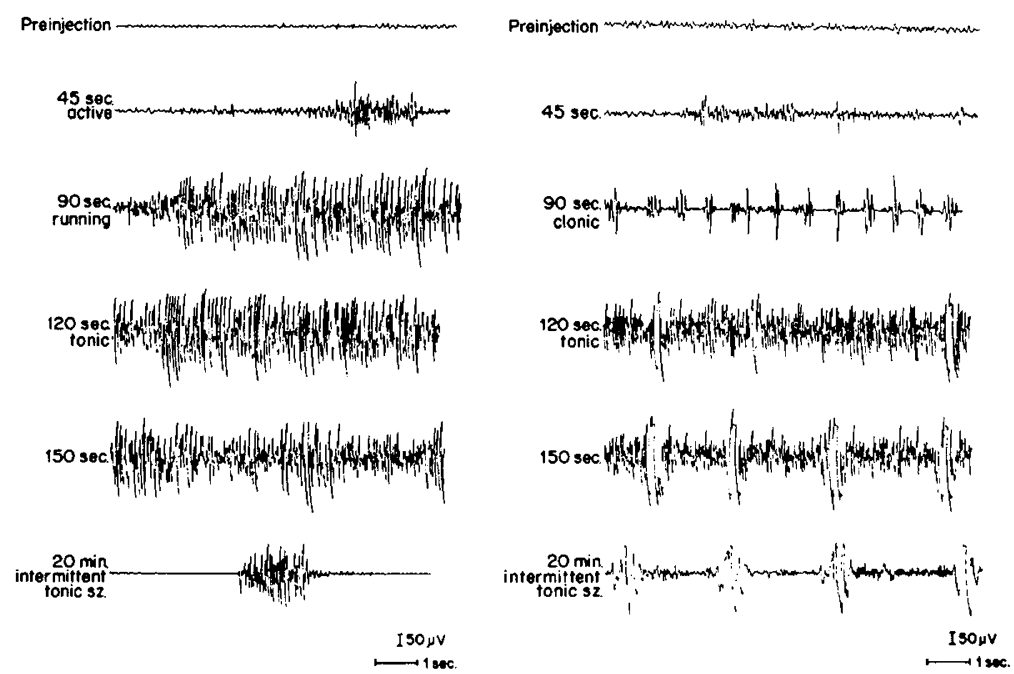

Fig. 1. Electroencephalograms of newborn rabbits and marmoset monkeys recorded from scalp electrodes during seizures induced by bicuculline.

animals became restless and agitated, as bursts of higher-voltage paroxysmal activity appeared in the tracing (Fig. 1). This hyperactivity evolved into constant running movements of all limbs, associated with loss of posture, so that the animal was lying on its side, paddling with all four limbs, with an EEG made of nearly continuous polyspikes (Fig. 1). As those increased in intensity, a tonic seizure developed and lasted approximately 15 s. These seizures were followed by a few multifocal clonic seizures interrupting postictal depression of behavioral and EEG activity. Tonic clinical and EEG seizures recurred periodically throughout the experiment with a progressive increase in the duration and intensity of postictal depression. Little difference in seizure intensity was noted between glucose and saline-injected animals. Marmosets had a similar response to bicuculline, characterized by increased activity with bursts of high voltage EEG activity, followed by clonic movements of the head and all four limbs with synchronous bursts of high voltage polyspikes, then by a tonic seizure with continuous high-voltage spikes, itself followed by clonic limb activity and EEG bursts (Fig. 1). Subsequent seizures were predominantly tonic but retained a more prominent clonic component than in rabbits.

Glucose. The effect of bicuculline seizures on blood and brain glucose concentration in newborn rabbits is shown in Figure 2. In untreated control rabbits, both blood and brain glucose concentrations were higher than expected; this may have reflected the stress of transportation and handling. Blood glucose concentration in the saline-treated rabbits remained close to control levels for the first $10-15$ min of seizures, falling to $33 \%$ of control $(p<0.01$ ) by $30 \mathrm{~min}$ (Fig. 2). Glucose-treated rabbits were hyperglycemic throughout the duration of the experiment.

Brain glucose in saline-treated rabbits fell rapidly after seizure onset ( $20 \%$ of control, $p<0.01-2 \mathrm{~min}$ ) despite the absence of hypoglycemia. After $10 \mathrm{~min}$ of seizure activity, when blood glucose was still in the normal range, mean brain glucose concentration was $0.08 \pm 0.077 \mathrm{mmol} / \mathrm{kg}$, less than $3 \%$ of control levels and it remained at this level after 15 or $30 \mathrm{~min}$ of seizure activity. Glucose injection prior to seizures prevented most of the severe brain glucose depletion found in saline-treated rabbits except at 2 min when it was $26 \%$ of control levels $(p<0.001)$ (Fig. 2). Unlike the results in the saline group, brain glucose steadily increased in glucose-treated rabbits as the duration of seizures lengthened. Even though the glucose concentration in glucose-treated rabbits was still relatively low after 5 and $10 \mathrm{~min}$ of seizures ( 41 and $43 \%$ of control, respectively, $p<0.01$ ), it was still greater than expected for unstressed rabbits.

Figure 3 depicts blood and brain glucose concentrations in newborn marmoset monkeys during bicuculline seizures. After

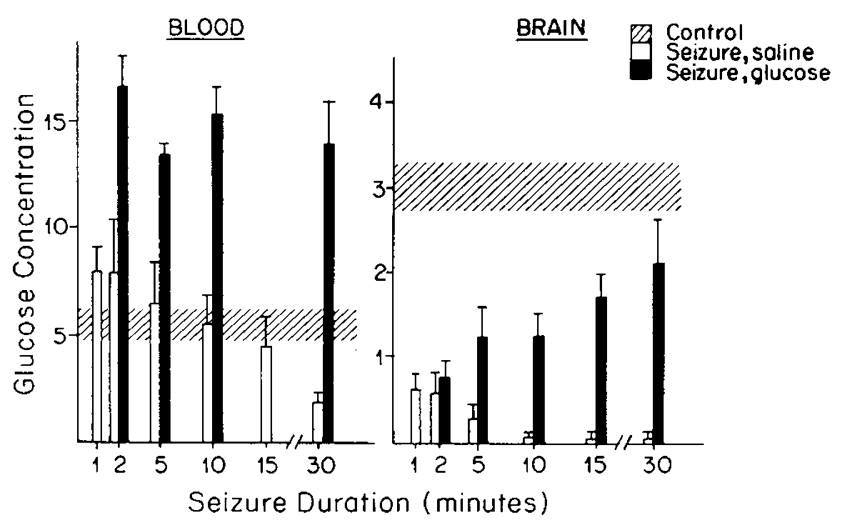

Fig. 2. Blood and brain glucose concentration during status epilepticus in newborn rabbits. Rabbits in which seizures were induced were injected with solutions of isotonic glucose or $\mathrm{NaCl}(5 \%$ of body weight subcutaneously) $30 \mathrm{~min}$ prior to bicuculline injection $(5 \mathrm{mg} / \mathrm{kg}$, intramuscular). Experimental animals were sacrificed by focused microwave irradiation at the times after seizure onset indicated in the figure. Blood glucose is expressed as $\mathrm{mmol} / \mathrm{l}$ and brain glucose as $\mathrm{mmol} / \mathrm{kg}$. The hatched area represents the mean value \pm SEM for untreated control rabbits $(n=18)$. Other points represent mean \pm SEM for following: Glucose treated-blood and brain: $n=3$ for each time point. Salinetreated: blood: $1 \min (n=4), 2 \min (n=7), 5 \min (n=15), 10$ and 30 $\min (n=5), 15 \min (n=10)$. Saline treated-brain: 1 and $30 \min (n=$ 4), $2 \min (n=7), 5 \min (n=12), 10 \min (n=5), 15 \min (n=9)$. For statistical analysis, data obtained from rats in the control group were pooled.

$30 \mathrm{~min}$ of seizures, severe reductions in brain glucose concentrations were observed. In fact, two animals had brain glucose concentrations of 0.06 and $0.08 \mathrm{mmol} / \mathrm{kg}$, respectively. Blood glucose in seizing marmosets while generally lower than in controls (seizure: $5.87 \pm 3.38$ versus control: $8.53 \pm 3.09 \mathrm{mmol} /$ $1 \pm \mathrm{SD})$ never fell below $2 \mathrm{mM}(36 \mathrm{mg} / \mathrm{dl})$ in any animal. Thus in newborn marmosets, as in newborn rabbits, brain glucose can be severely reduced by continuous seizures while blood glucose concentration is maintained close to physiological levels.

Lactate. Bicuculline seizures produced a sharp increase in blood lactate in both saline- and glucose-treated rabbits (Fig. 4). Most of the increase in both groups occurred within 2 min after seizure onset when lactate was elevated close to six times above control levels, compared to about an 8-fold increase after $30 \mathrm{~min}$ of seizures. Remarkably, blood lactate increased to about the same concentration in both glucose- and saline-treated rabbits 


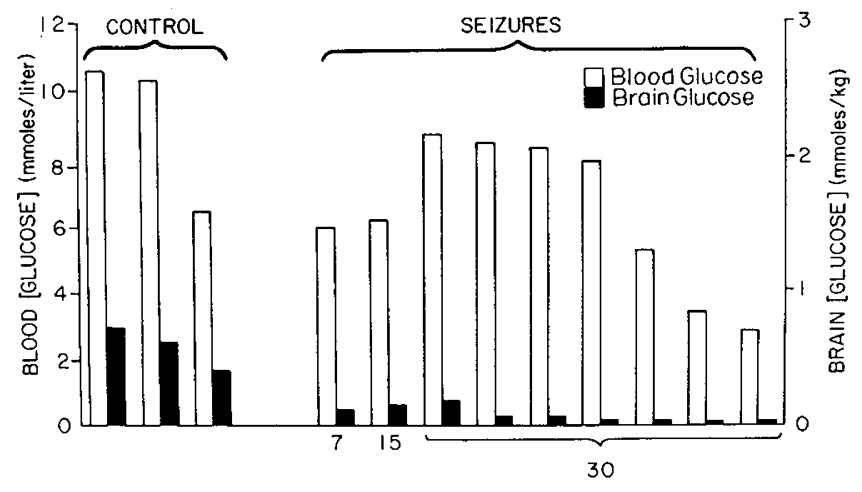

DURATION OF SEIZURE (min)

Fig. 3. The effect of status epilepticus on blood and brain glucose in newborn marmoset monkeys. Marmoset monkeys (4-7 days old) were injected with bicuculline $(5 \mathrm{mg} / \mathrm{kg}$, intramuscular) to induce seizures or the equivalent volume of isotonic $\mathrm{NaCl}$ (controls) and were sacrificed by immersion in liquid nitrogen at various times after seizure onset as indicated on the abscissa. Each pair of bars represents values of blood and brain glucose for a single marmoset.

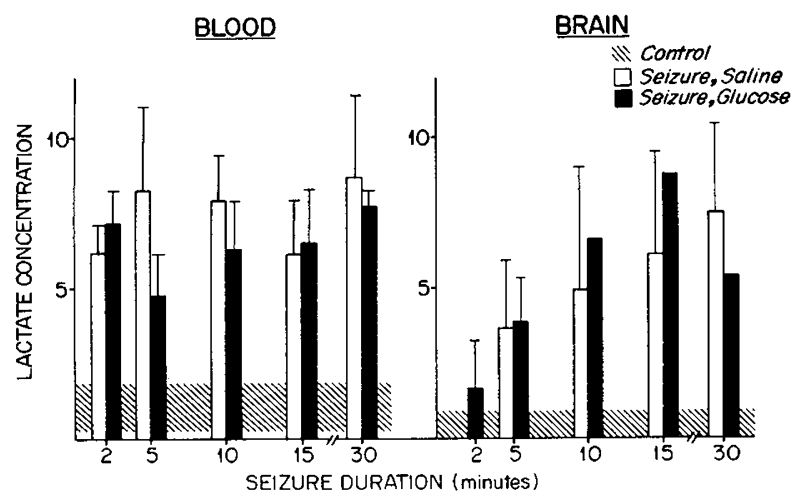

Fig. 4. Blood and brain lactate concentration during status epilepticus in newborn rabbits. Experimental conditions were the same as those described in the legend to Figure 2. Blood lactate is expressed as $\mathrm{mmol} /$ 1 and brain lactate as $\mathrm{mmol} / \mathrm{kg}$. The hatched area represents the mean \pm SEM for untreated control rabbits-blood $(n=15)$, brain $(n=12)$. The $n$ for each group is given below. Where standard error bars are not included in the graph $n<3$ and both $n$ and individual measurements are given. Glucose treated-blood: $n=3$ for each time point. Brain: 2 and $5 \min (n=3), 10 \mathrm{~min}(6.62), 15 \mathrm{~min}(10.08,7.47), 30 \mathrm{~min}(7.51$, 11.27). Saline-treated-blood: 2 and $30 \mathrm{~min}(n=3), 5$ and $10 \mathrm{~min}(n=$ 5), $15 \min (n=4)$. Brain: 5 and $10 \min (n=4), 15$ and $30 \min (n=3)$.

despite the greatly increased blood glucose concentrations in the former group. Brain lactate accumulation during seizures was similar in both glucose- and saline-treated rabbits. It did not bear a simple relationship to brain glucose since by $10 \mathrm{~min}$ after seizure onset brain glucose in saline-treated rabbits was depleted while brain lactate was slowly increasing. More likely, brain lactate in both groups of seizing rabbits reflected blood lactate concentrations.

\section{DISCUSSION}

The occurrence of brain glucose depletion during seizures in newborn marmosets (a species more mature at bith than the human), rats, and rabbits (species less mature at birth than humans) suggests that this phenomenon is seen in neonates of many species including primates. Our data suggest that mild hyperglycemia may be beneficial for the newborn during repetitive seizures as long as circulation is maintained, and underscore the dangers of hypoglycemia during seizures. Hypoglycemia can have devastating consequences for the neonate (4-6) and it is conceivable that the combination of brain glucose depletion with seizure activity, may be even more damaging to the brain than glucose depletion alone.

The therapeutic value of elevated blood glucose has been seriously questioned. Hyperglycemia has been associated with an adverse outcome from cerebral ischemia in adult rodents (7-11) and in humans following cardiac arrest (12). It was associated with more severe CNS damage following total asphyxia in the term monkey fetus $(13,14)$, and did not alter the outcome of neonatal hypoxia-ischemia (15). In contrast, hyperglycemia reduced the mortality rate of immature rodents during prolonged convulsions (2) and anoxic anoxia (16, 17). Presumably the harmful effects of hyperglycemia in ischemia or asphyxia arise from the local lactic acidosis. However, brain lactate concentrations in excess of $20 \mathrm{mmol} / \mathrm{kg}$ which are associated with cell damage $(18,19)$ are far above those found in our animals. Seizures in adult rats (20), newborn dogs (21), and newborn monkeys (22) result in increased cerebral blood flow. The immature blood-brain barrier contains a high content of monocarboxylic acid carrier (23) by which lactate can enter or leave the brain. This combined with sustained blood flow may insure that lactate cannot accumulate to levels which exceed the buffering capacity of brain tissue (24) and are incompatible with cell survival. Under physiological conditions brain glucose utilization is limited by glucose flux through phosphofructokinase and not by transport into brain. Hexokinase may play a secondary role in the regulation of glucose flux in the glycolytic pathway, but its low $\mathrm{Km}$ for glucose estimated at from 8 to $45 \times 10^{-6} \mathrm{M}(25-$ 27) assures almost total saturation of the enzyme by this substrate at normal intracellular brain glucose concentrations. During seizures, glucose in rabbit brain fell to a mean value of $8 \times 10^{-5}$ $M$ within 10 min despite normoglycemia. In seizing marmosets, brain glucose fell to less than $5 \times 10^{-4} \mathrm{M}$, and in two animals to $6 \times 10^{-5}$ and $8 \times 10^{-5} \mathrm{M}$, respectively. These values likely overestimate true intracellular glucose concentrations. The $3 \%$ correction used for contamination of brain tissue by blood is probably a lower limit during seizures when cerebral blood flow is increased and the brain vasculature is dilated. Furthermore, no correction was applied for glucose in the brain extracellular fluid. This compartment was estimated to comprise $15 \%$ of brain mass in the adult and to have a glucose concentration about half of that in blood (28). Even if the glucose concentration in the extracellular fluid compartment were substantially less than onehalf that in blood calculated brain intracellular glucose concentrations would approach zero. This calculation underscores the likelihood that true brain intracellular glucose concentration fell during seizures to levels which could not saturate hexokinase so that glucose transport into brain became rate-limiting for cerebral glucose utilization. In contrast, when animals were made hyperglycemic, brain glucose concentration remained well above $10^{-3}$ M during seizures.

The basis for these results likely reflects the physical nature of the immature blood-brain barrier. In rats during the 1 st wk of life glucose flux into brain from blood is only about $20 \%$ of that in adults $(29,30)$. These data suggest that the concentration of the glucose carrier per unit of brain weight is lower in the immature brain, probably as a result of lower capillary density. This is presumably why, when glycolysis is increased by seizures, more glucose is utilized than can be transported in. The protective effect of hyperglycemia can be understood by considering the kinetic properties of the transport system in the blood-brain barrier. From the Michaelis-Menten equation $\left(\mathrm{V}=\frac{\mathrm{Vmax}(\mathrm{S})}{\mathrm{Km}+(\mathrm{S})}\right)$

it can be calculated that at physiological blood glucose concentration $(5 \mathrm{mM})$ the glucose carrier whose $\mathrm{Km}$ is about $7 \mathrm{mM}$ is never saturated (3) and the blood-brain barrier is able to utilize only $42 \%$ of its maximal transport capacity for glucose. If blood glucose concentration were to fall to $1.5 \mathrm{mM}$ glucose transport 
across the blood-brain barrier would operate at an efficiency of $18 \%$. However, if blood glucose was elevated to $11 \mathrm{mM}$ then $61 \%$ of the maximal transport capacity for glucose would be available. Hyperglycemia did not modify the intensity of the convulsive seizures in the newborn rabits, and presumably the rate of glucose utilization in brain. Thus the presence of significant amounts of glucose in the brains of glucose-treated rabbits during prolonged seizures likely resulted from increased glucose transport associated with hyperglycemia.

\section{REFERENCES}

1. Wasterlain CG 1976 Effects of neonatal status epilepticus on rat brain development. Neurology 26:975-986

2. Wasterlain CG, Duffy TE 1976 Status epilepticus in immature rats. Protective effects of glucose on survival and brain development. Arch Neurol 33:821827

3. Curtiss DR, Duggan AW, Felix D, Johnston GAR 1970 GABA, bicuculline and central inhibition. Nature (Lond) 226:1222-1224

4. Anderson JM, Milner RDG, Strich SJ 1967 Effects of neonatal hypoglycaemia on the nervous system: a patholgoical study. J Neurol Neurosurg Psychiat 30:295-310

5. Banker BQ 1967 The neuropathological effects of anoxia and hypoglycemia in the newborn. Dev Med Child Neurol 9:544-550

6. Knoblach H, Sotos JF, Sherard ES Jr, Hodson WA, Wehe RA 1967 Prognostic and etiologic factors in hypoglycemia. Pediatrics 70:876-884

7. Pulsinelli WA, Waldman S, Rawlinson D, Plum F 1982 Moderate hyperglycemia augments ischemic brain damage: a neuropathologic study in the rat. Neurology 32:1239-46

8. Siemkowicz E, Gjedde A 1980 Post-ischemic coma in rat: effect of different pre-ischemic blood glucose levels on cerebral metabolic recovery after ischemia. Acta Physiol Scand 110:225-232

9. Siemkowicz E, Hansen AF 1978 Clinical restitution following cerebral ischemia in hypo- normo- and hyperglycemic rats. Acta Neurol Scand 58:1-8

10. Welsh FA, Ginsberg MD, Rieder W, Budd WW 1980 Deleterious effect of glucose pretreatment on recovery from diffuse cerebral ischemia in the cat. II. Regional metabolite levels. Stroke 11:355-363

11. Welsh FA, Sims RE, McKee AE 1983 Effect of glucose on recovery of energy metabolism following hypoxia-oligemia in mouse brain: dose dependence and carbohydrate specificity. J Cereb Blood Flow Metab 3:486-492

12. Longstreth WT, Iniu TS 1984 High blood glucose level on hospital admission and poor neurological recovery after cardiac arrest. Ann Neurol 15:59-63

13. Myers RE 1968 The clinical and pathological effects of asphyxiation in the fetal rhesus monkey. In: Adamsons K (ed) Diagnosis and Treatment of Fetal
Disorders. Springer Verlag, Berlin, pp 226-244

14. Myers RE 1972 The patterns of perinatal brain damage and their conditions of occurrence. Am J Obstet Gynecol 112:246-276

15. Voorhies T, Rawlinson DG, Vannucci RC 1982 The effect of glucose supplementation on neonatal hypoxia-ischemic brain damage. Neurol 32:A170 (abstr)

16. Holowach-Thurston J, Haubart RE, Jones EM, Ikossi MG, Pierce RW 1973 Decrease in brain glucose in anoxia in spite of elevated plasma of glucose levels. Pediatr Res 7:691-695

17. Holowach-Thurston J, Haubart RE, Jones EM 1974 Anoxia in mice: reduced glucose in brain with normal or elevated giucose in plasma and increased survival after glucose treatment. Pediatr Res 8:238-243

18. Myers RE 1977 Experimental models of perinatal brain damage: Relevance to human pathology. In: Gluck L (ed) Intrauterine Asphyxia in the Developing Fetal Brain. Chicago Yearbook Medical Publishers, Chicago, pp 37-97

19. Rehncrona S, Rosen I, Siesjo BK 1981 Brain lactic acidosis and ischemic cell damage: I. Biochemistry and neurophysiology. J Cereb Blood Flow Metabol 1:297-311

20. Ingvar M, Siesjo BK 1983 Local blood flow and glucose consumption in the rat brain during sustained bicuculline-induced seizures. Acta Neurol Scand 68:129-144

21. Young RSK, Osbakken MD, Briggs RW, Yagel SK, Rice DW, Goldberg SL $1984{ }^{31} \mathrm{P}$ Nuclear magnetic resonance study of cerebral high-energy phosphate metabolism during prolonged seizures in neonatal dogs. Ann Neurol 16:377 (abstr)

22. Hosokawa S, Yamashita Y, Veno H, Caveness WF 1977 Regional cerebral blood flow pattern in subcortical propagation of focal seizures in newborn monkeys. Ann Neurol 1:225-234

23. Cremer JE, Cunningham VJ, Pardridge WM, Braun LD, Oldendorf WH 1979 Kinetics of blood-brain barrier transport of pyruvate, lactate and glucose in suckling, weanling and adult rats. J Neurochem 33:439-445

24. Kraig RP, Pulsinelli W, Plum F 1984 Proton buffering of the brain during complete ischemia. Ann Neurol 16:111-112

25. Fromm HJ, Zewe V 1962 Kinetic studies of the brain hexokinase reaction. J Biol Chem 237:1661-1667

26. Grossbard L, Schimke RT 1966 Multiple hexokinases of rat tissues. Purification and comparison of soluble forms. $\mathbf{J}$ Biol Chem 241:3546-3560

27. Sols A, Crane RK 1954 Substrate specificity of brain hexokinase. J Biol Chem 210:581-595

28. Siesjo BK 1978 Utilization of substrates by brain tissues. Brain Energy Metabolism. John Wiley and Sons, New York, pp 101-130

29. Growdon WA, Bratton TS, Houston MC, Tarpley HL, Regen DM 1971 Brain glucose metabolism in the intact mouse. Am J Physiol 221:1738-1745

30. Moore TJ, Lione AP, Regen DM, Tarpley HL, Raines PL 1971 Brain glucose metabolism in the newborn rat. Am J Physiol 221:1746-1753

31. Buschiazzo PM, Yerrell EB, Regen DM 1970 Sugar transport across the bloodbrain barrier. Am J Physiol 219:1505-1513 